American Journal of Environmental Sciences 5 (5): 647-652, 2009

ISSN 1553-345X

(C) 2009 Science Publications

\title{
Monitoring Growing Season Length of Deciduous Broad Leaf Forest Derived From Satellite Data in Iran
}

\author{
${ }^{1}$ Sasan Babaei Kafaki, ${ }^{1}$ Asadollah Mataji and ${ }^{2}$ Seyed Armin Hashemi \\ ${ }^{1}$ Department of Forestry, Faculty of Agriculture and Natural Resources, \\ ${ }^{2}$ Department of Forestry, \\ Sciences and Researches Branch, Islamic Azad University, Tehran, Iran
}

\begin{abstract}
Problem statement: Leaf phenology describes the seasonal cycle of leaf functioning and is essential for understanding the interactions between the biosphere, the climate and biogeochemical cycles. This study aimed to quantify changes in plant phenology of deciduous broadleaf forests between the years 1982-1999 and investigate the relationships between the onset dates of phenology and climatic factors. Approach: We studied the climate changes effected on the growing season duration in vegetation of Iran, using the AVHRR/NDVI biweekly time-series data collected from 1982-1999 and concurrent mean temperature and precipitation data. The first estimated fastest changes of NDVI corresponded to the vegetation green-up and dormancy from the seasonal cycle of NDVI during 1982-1999. The onset dates of vegetation green-up and dormancy were determined based on the estimated rates and the NDVI seasonal cycles. Results: The results showed that over the study period, the growing season duration has lengthened by 0.94 days year ${ }^{-1}$ in study region. The green-up of vegetation has advanced in the spring by 0.63 days year ${ }^{-1}$ and the dormancy delayed in autumn by 0.32 days $y \mathrm{ear}^{-1}$. The onset date of green-up for all vegetation types negatively correlated with mean preseason temperature for almost all the preseason periods significant, suggesting that the warmer winters probably benefit an earlier green-up the following spring. Conclusion: Based on NOAA/AVHRR NDVI biweekly time-series data and concurrent climate information, it was estimated that the growing season duration of Iran's vegetation was significantly lengthened, primarily through an earlier green-up and a later dormancy during the period of 1982-1999.
\end{abstract}

Key words: Green up, phenology, NDVI, dormancy

\section{INTRODUCTION}

Phenology has emerged recently as an important focus for ecological research ${ }^{[3]}$. Leaf phenology describes the seasonal cycle of leaf functioning and is essential for understanding the interactions between the biosphere, the climate and biogeochemical cycles $^{[4,8,9,12]}$. Leaf phenology depends primarily on the climatic conditions for a given biome. It strongly affects land-surface boundary conditions and the exchange of matter and energy with the atmosphere, influencing the surface albedo, roughness and the dynamics of the terrestrial water cycle ${ }^{[8]}$. Furthermore, the timing and progression of plant development may provide information to help researchers make inferences about the conditions of plants and their environment such as soil moisture, soil temperature, illumination, temperature ${ }^{[12]}$. Changes in the phonological events may therefore signal important year-to-year climatic variations or even global environmental change ${ }^{[1]}$. Several biophysical as well as terrestrial ecological models relating to climate change studies require phenology information at large spatial scales. Satellite remote sensing provides powerful techniques that can monitor and characterize phenological trends at large scales ${ }^{[18]}$. With a broad spatial coverage and high temporal resolution, The Normalized Difference Vegetation Index (NDVI) timeseries data was derived from (NOAA)/(AVHRR) which have been available since the 1980s. The Advanced Very High-Resolution Radiometer (AVHRR) of the National Oceanic and Atmospheric Administration (NOAA) NDVI datasets provides unique opportunities for monitoring terrestrial vegetation conditions at regional and global scales ${ }^{[20]}$ and has widely been used in research areas of NPP ${ }^{[10]}$, vegetation coverage ${ }^{[8,16,23]}$,

Corresponding Author: Seyed Armin Hashemi, Department of Forestry, Faculty of Natural Resources, Lahijan Branch, Islamic Azad University, Iran 
biomass $^{[7]}$ and phenology ${ }^{[6,12]}$. Normalized difference Vegetation Index (NDVI), which is derived from infrared channel and near-infrared channel remote sensing data, is a good indicator of photosynthesis (vegetation activity).Disease, competition, soil factors and weather conditions can profoundly influence plant phonological status ${ }^{[4]}$. Evidence from remote sensing data $^{[8,16,23]}$ all revealed that the spring advanced and growing season duration significantly lengthened over the past two decades at the middle and high latitudes in the northern hemisphere. The global warming has been suggested to be the major cause of the advance and extension of the growing season ${ }^{[5,16,23]}$.

NOAA/AVHRR NDVI data set and climate records were used to examine the recent trends in plant phenology in the selected zone of Iran from 1982-1999. The NDVI data set was at a spatial resolution of $8 \times 8 \mathrm{~km}^{2}$ and 15 day interval. This study aims to quantify changes in plant phenology of deciduous broadleaf forests between the years 1982-1999 and investigate the relationships between the onset dates of phenology and climatic factors.

\section{MATERIALS AND METHODS}

Study area: The research has performed in selected zone of Iran (Fig. 1). The selected zone area is $183182 \mathrm{~km}^{2}$. This region is covered by deciduous broadleaf forests, grasslands, shrubs, cultivation. The mean annual precipitation in deciduous broadleaf forests is $877 \mathrm{~mm} \mathrm{year}^{-1}$. The scope of the study was limited to one vegetation type as follows: Deciduous Broad leaf forest (Fig. 1).

Data: The Advanced Very High Resolution Radiometer (AVHRR) data from NOAA's series of polar-orbiting meteorological satellites are used extensively to study regional, continental and global phenomena. The most popular application of these data is to monitor and evaluate vegetation over the land surfaces. Among the available types of satellite data, AVHRR data is outstanding for its temporal resolution (the satellites pass above each location twice daily). NDVI data at a spatial resolution of $8 \times 8 \mathrm{~km}^{2}$ and 15 day interval were acquired from the Global Inventory Monitoring and Modeling Studies (GIMMS) group derived from the NOAA/AVHRR Land data set for the period January 1982 to December 1999. The dataset is known for its high quality, having been calibrated to eliminate noise from volcano eruptions, solar angle and sensor errors and has been widely used in studies on vegetation dynamics at regional and global scales ${ }^{[7,14,23]}$.

In order to eliminate the impact of bare and sparsely vegetated regions, only grid cells with annual mean NDVI greater than 0.1 during the 18 year period were used in this study.

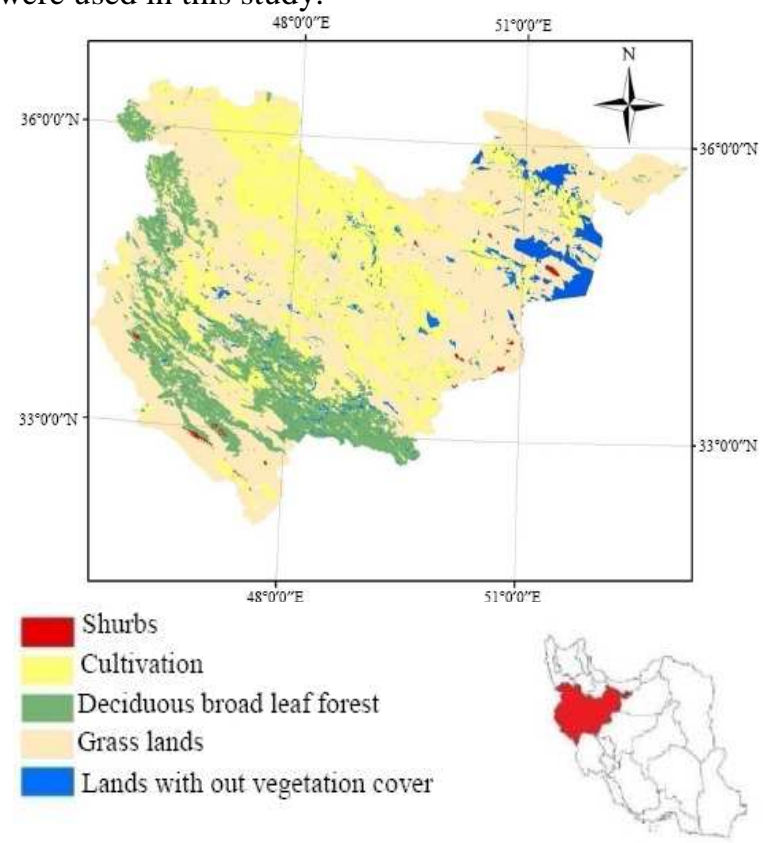

Fig. 1: Distribution vegetation types in study area of Iran. (Forest, Range and Watershed Organization of Iran, 1995)

Monthly climate data used in this study include temperature and precipitation data, produced by Iran meteorological organization (www.irimet.net), for the years 1982-1999. Biweekly means temperature and precipitation data were compiled from the 1982-1999 temperature/precipitation databases of weather stations Iran in whole study area.

Vegetation type data were obtained from a digitized 1:2000000 vegetation map of Iran (Forest, Range and Watershed Organization of Iran) Vegetation was grouped as: Deciduous broadleaf forest, shrubs, grasslands, Cultivation, (Fig. 1). As mentioned above, Deciduous Broad leaf forest was included in the study.

Methods: Was identified the period of greatest increase in NDVI as the beginning of growing season ${ }^{[6,12,21,22]}$. The first estimated fastest changes of NDVI corresponded to the vegetation green-up and dormancy from the seasonal cycle of NDVI during 1982-1999. The onset dates of vegetation green-up and dormancy were determined based on the estimated rates and the NDVI seasonal cycles.

Procedures used to determine the onset dates of phenological event from (NDVI) time series are shown in Fig. 2. For determining the 18 year averaged 
seasonal NDVI curves, we computed the 18 year averaged seasonal NDVI curves for the deciduous broadleaf forest type was set at 15 day intervals from the whole data during from1982-1999. For determining the rates of the changes in the average seasonal NDVI curves, we computed the NDVI ratio from (Eq. 1). The NDVIratio were computed from the 18 year averaged NDVI seasonal curves for the deciduous broadleaf forest type. The NDVIratio, from the series of consecutive 15 day periods was calculated:

$$
\operatorname{NDVIratio}(t)=\frac{\operatorname{NDVI}(t+1)-\operatorname{NDVI}(t)}{\operatorname{NDVI}(t)}
$$

In this equation $\mathrm{t}$ is time. The timing of greatest NDVI change, namely the maximum and minimum values of NDVIratio was then used, to determine the average onset dates of vegetation green up and dormancy.

To determine the NDVI threshold related to the vegetation green up and dormancy as follows. The time $\mathrm{t}$ was detected with the minimum NDVIratio and then the corresponding $\operatorname{NDVI}(\mathrm{t}+1)$ at time $(\mathrm{t}+1)$ as the NDVI threshold for the onset date of vegetation dormancy was used. And also, the time t was detected with the maximum NDVIratio and then the corresponding NDVI(t) as the NDVI threshold for the onset date of green-up was used.

For fitting a smooth NDVI seasonal curve as a function of time, in general, for a pixel, with increasing Julian day, its NDVI value gradually increases first and then decreases after arriving its maximum.

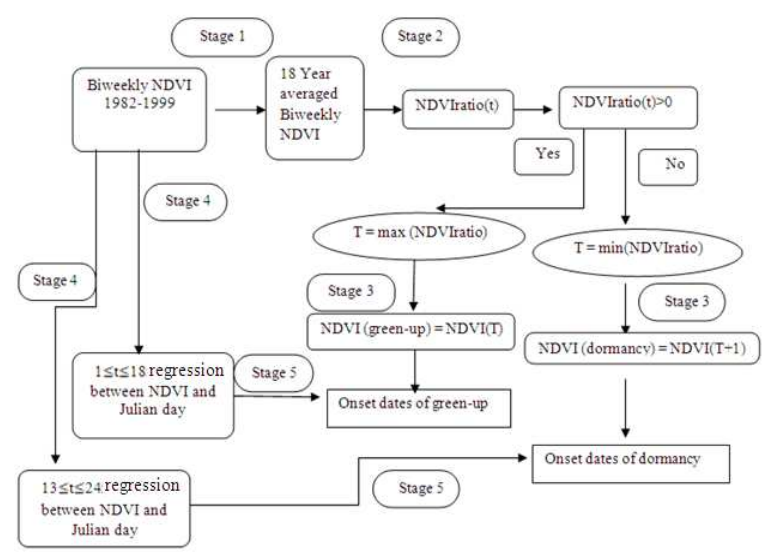

Fig. 2: NDVI(green-up) is the NDVI threshold of the onset of green-up, NDVI(dormancy) is the NDVI threshold of the onset of vegetation dormancy, the $\mathrm{t}$ is biweekly period, $\operatorname{NDVI}(\mathrm{t})$ is the NDVI in period $t$, NDVIratio $(t)$ is the ratio of NDVI change between the period $t$ and the period $\mathrm{t}+1$

Therefore, a least-square regression analysis of the relationship between the biweekly NDVI time-series data from January to September and from July to December was done and the corresponding Julian day for the entire study area and vegetation types for each year was calculated (Eq. 2), to represent the seasonal changes in NDVI as a function of Julian day. Mostly, this seasonal NDVI curve can fit an inverted parabola equation:

NDVI $=a+a_{1} x^{1}+a_{2} x^{2}+a_{3} x^{3}+\ldots \ldots+a_{n} x^{n}$

This equation $\mathrm{x}$ is the Julian days. Because of the impact of some non vegetation effects of cloud, atmosphere, solar zenith angle and other factors, some NDVI values are lower than their two adjacent ones. Obviously, using Eq. 2 can help smooth these abnormal values. A sixth degree polynomial function $(n=6)$ was applicable to the regression in most cases.

For identifying the onset dates of vegetation greenup and dormancy, the onset dates of vegetation greenup and dormancy were determined for the deciduous broadleaf forest type for each year, using the polynomial equations obtained in stage 4 and the NDVI thresholds calculated in stage 3 . These onset dates were then used to analyze their trends over year.

\section{RESULTS}

The early May was recognized as the mean onset period of vegetation green-up while early November as the mean onset period of vegetation dormancy for the entire national level. Table 1 lists the vegetation greenup and dormancy and their corresponding thresholds of NDVI and temperature for each vegetation type.

Figure 3 shows the seasonal variations in the 18 year averaged NDVI and temperature at the interval of 15 days for the entire study area.

In contrast, the mean onset dates of dormancy do not differ among vegetation types; all occur in early November. The highest NDVI thresholds for the onset dates of green-up (0.312) and dormancy (0.331) occur in broad leaf forests. The onset date of green-up over study area has significantly advanced over the past 18 years $\left(\mathrm{R}^{2}=0.71, \mathrm{p}=0.005\right)$, with an annual advance of 0.63 days year ${ }^{-1}$ (Fig. $4 \mathrm{a}$ ). The onset date of vegetation dormancy was delayed from 1982$1999\left(\mathrm{R}^{2}=0.44, \mathrm{p}=0.006\right)$, with an annual delay of 0.32 days year ${ }^{-1}$ (Fig. 4b). The length of the growing season has increased by 0.94 days year $^{-1}$ from 1982-1999 ( $\left.\mathrm{R}^{2}=0.65, \mathrm{p}=0.002\right) \quad$ (Fig. 4c).

Table 1: Average NDVI threshold and Temperature threshold of vegetation green-up and vegetation dormancy from 19821999

\begin{tabular}{|c|c|c|}
\hline & NDVI threshold & Temperature threshold $\left({ }^{\circ} \mathrm{C}\right)$ \\
\hline Vegetation type & $\mathrm{a}$ & a \\
\hline
\end{tabular}




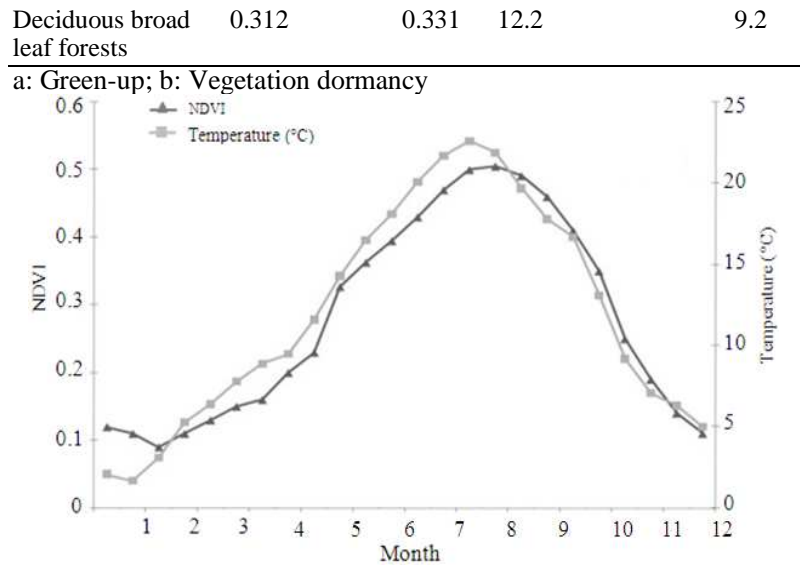

Fig. 3: Seasonal curves in the 18 year averaged biweekly NDVI and temperature

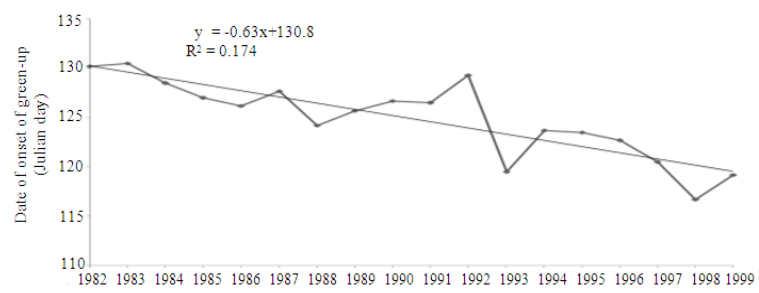

(a)

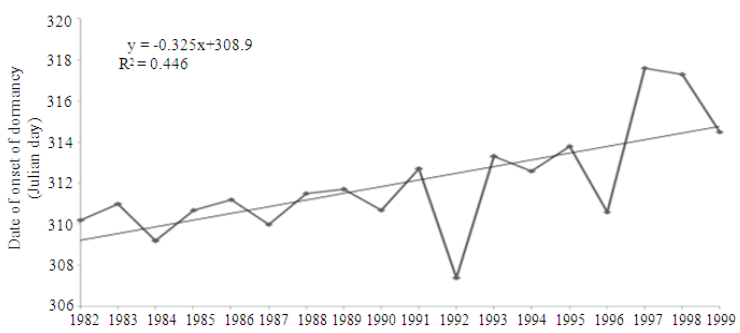

(b)

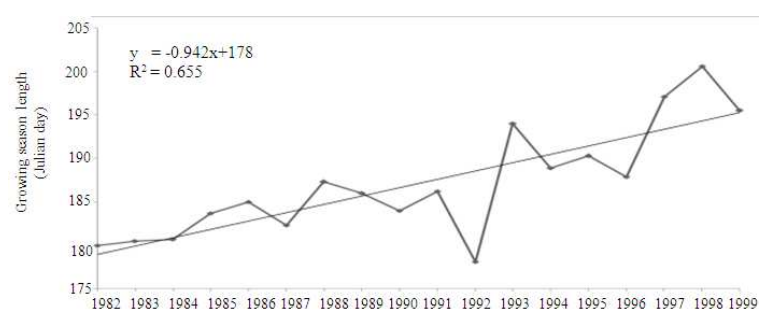

(c)

Fig. 4: Variation in the onset dates of (a) green-up, (b) vegetation dormancy and (c) growing season length from 1982-1999

Deciduous broad leaf forest exhibit advanced green-up and dormancy (Fig. 4b). Results of Green-up trends in relation to climate shows, when analyzing the relationships between the onset dates of green-up and the climatic variables, we calculated the average

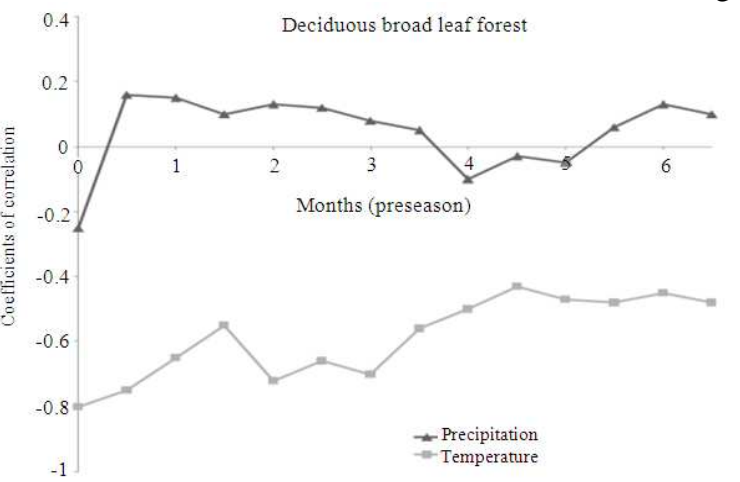

Fig. 5: Correlation coefficients between onset dates of green-up and mean preseason temperature and precipitation in different preseason periods. The $\mathrm{x}$-coordinate (i) denotes the period from i months before early May through early May

temperature and cumulative precipitation before the onset date of green-up and since preceding date of dormancy. We computed the correlation coefficients between these average climate variables and the onset dates of green-up. We used the term 'preseason' to refer to the period before the mean onset dates to analyze the relationships between the onset date and preseason climatic variables ${ }^{[21]}$. According to such a definition, the length of preseason expands to half month periods, from early May to the preceding November. Figure 5 demonstrates the correlation coefficients between onset dates of green-up and mean preseason temperature and precipitation by the vegetation type. The onset date of green-up for Deciduous Broad leaf forest type negatively correlated with mean preseason temperature for almost all the preseason periods significant (Fig. 5), the warmer winters probably benefit an earlier green-up the following spring. The cumulative temperature during the 2 months just before the onset of green-up significantly contributes to the forest growth (Fig. 5). The onset date of the green-up is not significantly coupled with preseason cumulated precipitation for the deciduous broad leaf forest (Fig. 5).

The mean temperature at that time could have the greatest influence in activating the green-up of the study area. The greatest correlation is in the preceding 2 months (Fig. 5).

The averaged temperature and cumulated precipitation were calculated during the growing season from early May to early November by increasing each half-month from the onset date of vegetation dormancy and the obtained temperature and the precipitation values for 10 periods. The correlation coefficients of these 'pre dormancy' climatic conditions with the onset 
date of vegetation dormancy were computed for the 1982-1999.

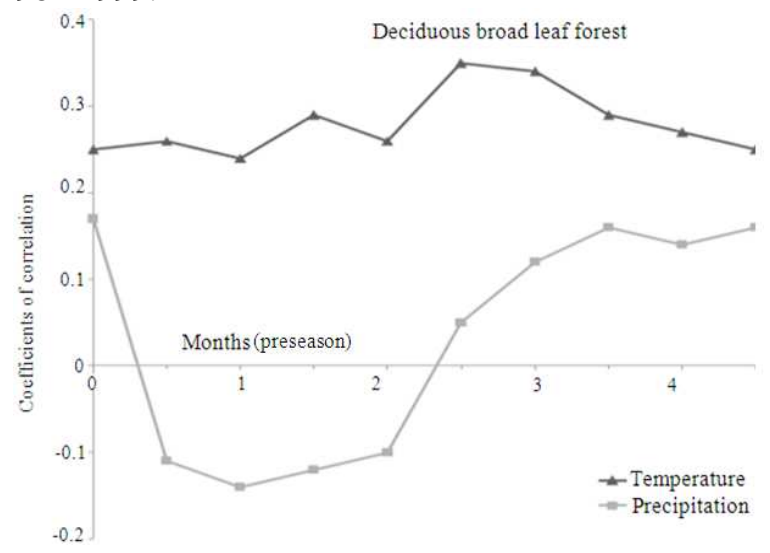

Fig. 6: Correlation coefficients between the onset date of vegetation dormancy and preseason mean temperature and precipitation for different preseason periods. The $\mathrm{x}$-coordinate (i) denotes the period from $i$ months before early November to early November

The increased temperature during the preceding growing season postponed the dormancy of vegetation at regional scale. The warmer preceding temperatures led to a delay of the dormancy (positive correlation) for deciduous Broad leaf forest type (Fig. 6). The relationship between the onset date and the preceding cumulative Precipitation by deciduous Broad leaf forest type showed no significant correlation for the deciduous broadleaved forest type (Fig. 6).

\section{DISCUSSION}

The mean NDVI in the region shows the greatest increase the early May and the greatest decrease early November, respectively. A 'sudden change' in NDVI can be related to the onset or cessation of 'significant photosynthetic activity' ${ }^{[6,12]}$. Various biomes require the use of different NDVI thresholds ${ }^{[12]}$. For example The NDVI threshold of deciduous broadleaf forests higher than NDVI threshold of grasslands. It is important to note that the phenological events in this study are determined by satellite data only. the spring events were increasingly occurring earlier in the recent decades ${ }^{[2,4,8,13,16,19,23]}$. This study estimated that the onset date of the green up of the selected zone of Iran advanced on average by 0.63 days year ${ }^{-1}$ from 19821999. Some evidence also indicates a later onset of autumnal phenological events ${ }^{[2,17]}$. This study estimated that the onset date of vegetation dormancy of the selected zone of Iran was delayed with an annual delay of 0.32 days year ${ }^{-1}$ from 1982-1999. Increasing in growing season length could increase the mean forest net primary production ${ }^{[19]}$. The length of the growing season duration mainly impacts the interannual variability of plant growth and thereby, also strongly affects the net carbon dioxide uptake ${ }^{[11]}$. This study estimated that the mean onset date of length of the growing season over study area has significantly advanced with an annual advance of 0.94 days year ${ }^{-1}$. The global warming induced by increasing atmospheric greenhouse gases, has been suggested to be the major cause of the advance and extension of the growing season $^{[5,16,23]}$. In this study, during last 18 years in entire study area means annual temperature increased $0.6^{\circ} \mathrm{C}$. The onset date of the green-up is not significantly coupled with preseason cumulated precipitation for the forest. It may be associated with their growth environments ${ }^{[6]}$, Forests are always located in areas with relatively abundant rainfall.

\section{CONCLUSION}

Based on NOAA/AVHRR NDVI biweekly timeseries data and concurrent climate information, it was estimated that the growing season duration of Iran's vegetation was significantly lengthened, primarily through an earlier green-up and a later dormancy during the period of 1982-1999. This strongly supports the lengthening of the growing season duration owing to the global warming at the northern high latitudes in the recent decades.

\section{ACKNOWLEDGMENT}

I express my hearty gratitude to Forest, Range\& Watershed Organization of Iran (www.frw.org.ir) and members of archive.

\section{REFERENCES}

1. Botta, A., N. Viovy, P. Ciais, P. Friedlingstein and P. Monfray, 2000. A global prognostic scheme of leaf onset using satellite data. Global Change Biol., 6 : 709-725. http://www.ingentaconnect.com/content/bsc/gcb/20 00/00000006/00000007/art00001

2. Chmielewski, F.M. and T. Rotzer, 2001. Response of tree phenology to climate change across Europe. Agric. For. Meteorol., 108: 101-112. http://www.ingentaconnect.com/content/els/01681 923/2001/00000108/00000002/art00233

3. Menzel, A., 2000. Trends in phenological phases in Europe between 1951 and 1996. Int. J. 
Biometeorol., $\quad 44$ : 76-81. DOI: 10.1007/s004840000054

4. Menzel, A., N. Estrella and P. Fabian, 2001. Spatial and temporal variability of the phenological seasons in Germany from1951 to 1996. Global Change Biol., 7: 657-666. http://www3.interscience.wiley.com/journal/12084 6179/abstract?CRETRY $=1 \&$ SRETRY $=0$

5. Menzel, A. and P. Fabian, 1999. Growing season extended in Europe. Nature, 397: 659-659. DOI: 10.1038/17709

6. Moulin, S., L. Kergoat and N. Viovy, 1997. Global-scale assessment of vegetation phenology using NOAA/AVHRR satellite measurements. J. Climate, 10: 1154-1170. http://www.cesbio.upstlse.fr/data_all/annuaire/kergoat/pdf/jclimate97.pdf

6. Myneni, R.B., J. Dong, C.J. Tucker, R.K. Kaufmann and P.E. Kauppi et al., 2001. A large carbon sink in the woody biomass of Northern forests. Proc. Natl. Acad. Sci. USA., 98: 14784-14789. http://www.pnas.org/content/98/26/14784.full

7. Myneni, R.B., C.D. Keeling, C.J. Tucker, G. Asrar and R.R. Nemani, 1997. Increased plant growth in the northern high latitudes from 1981 to 1991. Nature, 386: 698-702. DOI: 10.1038/386698a0

8. Nemani, R.R., C.D. Keeling, H. Hashimoto, W.M. Jolly and S.C. Piper et al., 2003. Climate driven increases in global terrestrial net primary production from1982-1999. Science, 300: 1560-1563. DOI: $10.1126 /$ science. 1082750

9. Paruelo, J.M., H.E. Epstein, W.K. Lauenroth and I.C. Burke, 1997. ANPP estimates from NDVI for the Central Grassland Region of the United States. Ecology, 78: 953-958. http://cat.inist.fr/?aModele $=$ afficheN\&cpsidt $=2685428$

10. Randerson, J.T., C.B. Field, I.Y. Fung and P.P. Tans, 1999. Increases in early season ecosystem uptake explain recent changes in the seasonal cycle of atmospheric $\mathrm{CO}_{2}$ at high northern latitudes. Geophys. Res. Lett., 26: 2765-2768.

http://cat.inist.fr/?aModele $=$ afficheN\&cpsidt $=1934313$

11. Reed, B.C., J.F. Brown and D. Vanderzee, 1994. Measuring phonological variability from satellite imagery. J. Veg. Sci., 5: 703-714. http://www.opuluspress.se/index.php?page=shop/ar ticle_abstract $\&$ product_id=8\&Itemid=56\&option= com_phpshop\&article $=16706 \& n r=-1$

12. Schwartz, M.D. and B.E. Reiter, 2000. Changes in North American spring. Int. J. Climatol., 20: 929-932. http://www3.interscience.wiley.com/journal/72509 480/abstract

13. Slayback, D.A., J.E. Pinzon, S.O. Los and C.J. Tucker, 2003. Northern hemisphere photosynthetic trends 1982-1999. Global Change Biol., 9: 1-15. http://www.gimms.gsfc.nasa.gov/publications/pdfs/ SlaybackPinzon03.pdf

14. Suzuki, R., T. Nomaki and T. Yasunari, 2003. West east contrast of phenology and climate in northern Asia revealed using a remotely sensed vegetation index. Int. J. Biotechnol., 47: 126-138. DOI: $10.1007 / \mathrm{s} 00484-003-0164-4$

15. Tucker, C.J., D.A. Slayback, J.E. Pinzon, S.O. Los, R.B. Myneni and M.G. Taylor, 2001. Higher northern latitude normalized difference vegetation index and growing season trends from 1982 to 1999. Int. J. Biometeorol., 45: 184-190. DOI: $10.1007 / \mathrm{s} 00484-001-0109-8$

16. Walther, G.R., E. Post. And P. Convey, 2002. Ecological responses to recent climate change. Nature, 416: 389-395. DOI: 10.1038/416389a

17. White, M.A., F. Hoffman, W.W. Hargrove and R.R. Nemani, 2005. A global framework for monitoring phonological response to climate change. Geophys. Res. Lett., 32: 704-705. http://research.esd.ornl.gov/ hnw/GRL_accepted_ phenoregions.pdf

18. White, M.A., S.W. Running and P.E. Thornton, 1999.The impact of growing-season length variability on carbon assimilation and evapotranspiration over 88 years in the eastern US deciduousforest. Int. J. Biometeorol., 42: 139-145. http://www.ncbi.nlm.nih.gov/pubmed/10083835

19. Yang, Y., L. Yang and J.W. Merchant, 1997. An assessment of AVHRR/NDVI-ecoclimatological relations in Nebraska. USA. Int. J. Remote Sens., 18: 2161-2180.

http://www.informaworld.com/smpp/ftinterface?co ntent $=a 713858491 \& \mathrm{rt}=0 \&$ format $=$ pdf

20. Yu, F., K.P. Price, J. Ellis and P. Shi, 2003. Response of seasonal vegetation development to climatic variations in eastern central Asia. Remote Sens. Environ., 87: 42-54.

http://cat.inist.fr/?aModele $=$ afficheN\&cpsidt $=1518$ 8194

21. Zhang, X., M.A. Friedl and C.B. Scahaaf, 2003. Monitoring vegetation phenology using MODIS. Remote Sens. Environ., 84: 471-475. DOI: 10.1016/S0034-4257(02)00135-9

22. Zhou, L., C.J. Tucker, R.K. Kaufmann, D. Slayback, N.V. Shabanov and R.B. Myneni, 2001. Variations in northern vegetation activity inferred from satellite data of vegetation index during 1981 to 1999. J. Geophys. Res. Atmos., 106: 20069-20083. http://www.agu.org/pubs/crossref/2001/2000JD000 115.shtml 